\title{
Lymphoedema in Hereditary Recurrent Cholestasis from Birth
}

\author{
ØYSTEIN AAGENAES, HELGE SIGSTAD, and RAGNAR BJØRN-HANSEN \\ From the Departments of Pediatrics, Internal Medicine A, and Radiology, University Hospital, Rikshospitalet, Oslo, \\ Norway
}

Aagenaes, Ø., Sigstad, H., and Bjørn-Hansen, R. (1970). Archives of Disease from birth. An inherited disorder characterized by a combination of lymphoedema and intrahepatic cholestasis is described in a Norwegian kindred. The jaundice is evident soon after birth, and recurrent episodes occur throughout life. The oedema starts at about school age and subsequently progresses; it is due to hypoplasia of the lymph vessels of the lower extremities. The cause of the cholestasis has not been established, but a structural intrahepatic developmental defect is suggested.

In 1968 (Aagenaes, van der Hagen, and Refsum), a family was described where 16 patients in 7 sibships suffered from cholestasis from birth. Oedema in the lower extremities developed in later childhood, the cause of which was not at that time established. This report describes further studies of the cause of oedema in these patients.

\section{Clinical Course}

Liver disease. The clinical course of the liver disease in children with this condition has been described by Aagenaes $e t$ al. (1968), and that in adult patients by Sigstad et al. (1970). A short summary is given here, and a pedigree of the family is shown on Fig. 1. The cholestasis was always recognized shortly after birth. The jaundice persisted from 1 year to more than 7 . During the cholestatic period, all patients had hepatomegaly, abnormal liver function, and a severe malabsorption picture. Normal growth with normal absorption and liver function was resumed with the spontaneous resolution of the cholestasis. All adult patients have had at least one cholestatic phase, and some have had recurrent periods of cholestasis, provoked by anaesthesia, pregnancy, or for no known reason.

Liver biopsy during infancy showed giant cell transformation and intrahepatic cholestasis, with slight increase of connective tissue in the periportal tracts and around the central veins. The adult cases showed an intracanalicular cholestasis during the jaundiced periods, and a variable degree of increase in connective tissue. Signs of portal hypertension were absent.

Oedema. Peripheral oedema has never been

Received 9 April 1970. recognized at birth. In the pre-school years some children have had slight pedal oedema, and all have somewhat thick, stout legs at this age, with slowly progressive oedema through the school years. Fig. 2 (XI 4) shows a 17-year-old patient, with oedema involving also the scrotum. At this stage the oedema may be relieved by elevation of the legs periodically or by diuretics.

Years later, if the oedema is not treated, the condition deteriorates and becomes irreversible, as shown in the 27-year-old man (XIII 7) in Fig. 3. One patient, now 34 (XII 14) has undergone plastic surgery on both legs because of the elephantiasis. The recurrent episodes of cholestasis have not affected the tendency to oedema; in fact some patients have thought that the oedema improved in the cholestatic phases. Some have had a tendency to lymphangitis.

\section{Investigations}

The lymph vessels in the lower extremities have been investigated in 3 adults and 3 children, including complete lymphangiography of one leg in the adults and in the oldest child (XI 2, XI 4, XIII 3, and XIII 7). A modification of the technique described by Kinmonth, Taylor, and Harper (1955) was used. In the smallest children, where full anaesthesia was required for a lymphangiogram, a screening test with intracutaneous injection of Patent blue dye (Kinmonth et al., 1957) has been used.

At dissection there was a striking reduction in the number of lymphatics. The Patent blue injected for visualization of the lymphatics tended to show an abnormal intradermal spread. The lymphangiograms were abnormal in all cases examined, with abnormal filling of numerous collateral pathways, dermal backflow, and delayed clearing of the contrast. In the patient with the most severe lymphoedema (XIII 7) no 690 


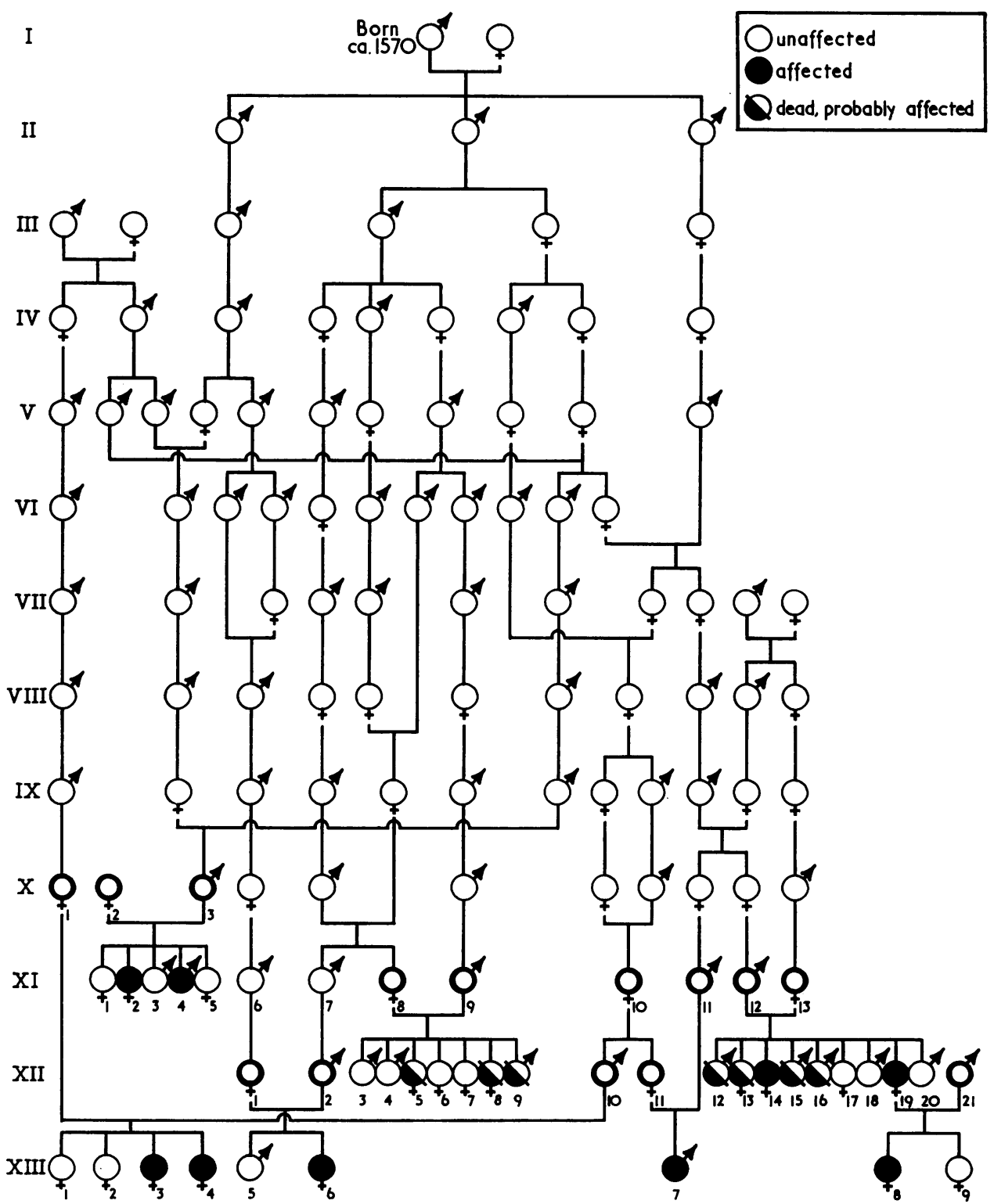

FIG. 1.-Pedigree of the family with congenital cholestasis and hereditary lymphoedema. Parents of patients are indicated by thick outlines to symbols.

normal lymphatic vessels were demonstrable, and there was marked dermal backflow (Fig. 4). (Filling was somewhat poor due to rupture of the small lymphatic vessel after injection of $2 \mathrm{ml}$. contrast.) In two sibs (XI 2 and XI 4) with a lesser and more varying degree of oedema (Fig. 2), lymphangiograms showed filling of numerous collateral pathways and delayed clearing of the contrast at 24 hours (Fig. 5). The lymphangiogram of the 8-year-old girl (XXIII 3) showed a reduced number of lymphatics in the calf and thigh, but was otherwise normal.

The dye screening test was carried out in 3 children. In patients XIII 3 and XIII 4, this revealed no abnormality, but in patient XIII 6 the dye showed pronounced dermal backflow (Fig. 6), strongly suggesting lymph vessel abnormality. None of the lymphangiograms 


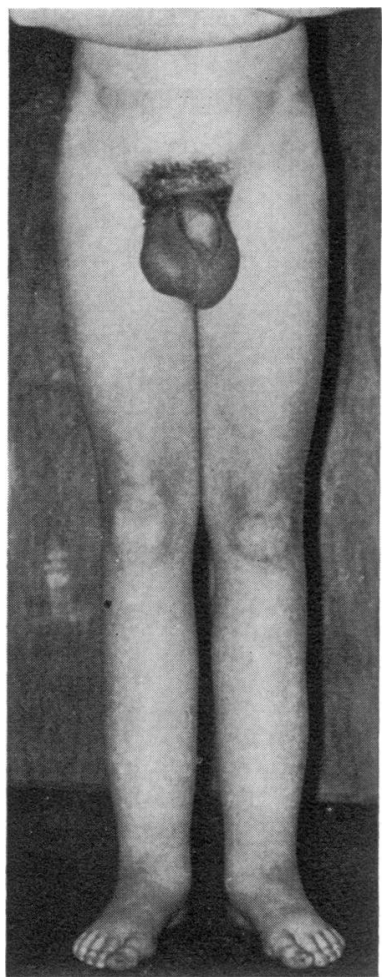

FIG. 2.-Lymphoedema of lower extremities and scrotum in patients $X I 4$, at age 17.

showed any abnormality of the thoracic duct or of the intra-abdominal lymphatics.

Serum protein values in the patients with the tendency to oedema are shown in the Table. In a few cases serum albumin levels were occasionally low enough possibly to cause slight oedema, but with subsequent normal values despite increasing oedema. As the Table shows, there was a slight tendency for the serum albumin to be lower in cholestatic phases, but serum protein changes fail to explain the tendency to oedema outside the cholestatic periods.

Serum thiamine levels were the same as in a control group, and treatment with high dosage of thiamine did not alter the oedema, so that thiamine deficiency was also eliminated as a cause of the oedema.

Urine aldosterone excretion was either normal or slightly high (10-20 $\mu \mathrm{g}$./day), except in one pregnant patient (XII 19) where the excretion was $100 \mu \mathrm{g}$./day.

In cholestatic periods, at least when these were prolonged, patients developed a slight peripheral neuropathy with loss of tendon reflexes and a borderline nerve conduction velocity. This may explain slight trophic oedema, as in patients with diabetic neuropathy, but the degree of oedema, and the fact that it persists after improvement in the peripheral neuropathy, argue against an autonomic neural lesion as the primary cause of the oedema.

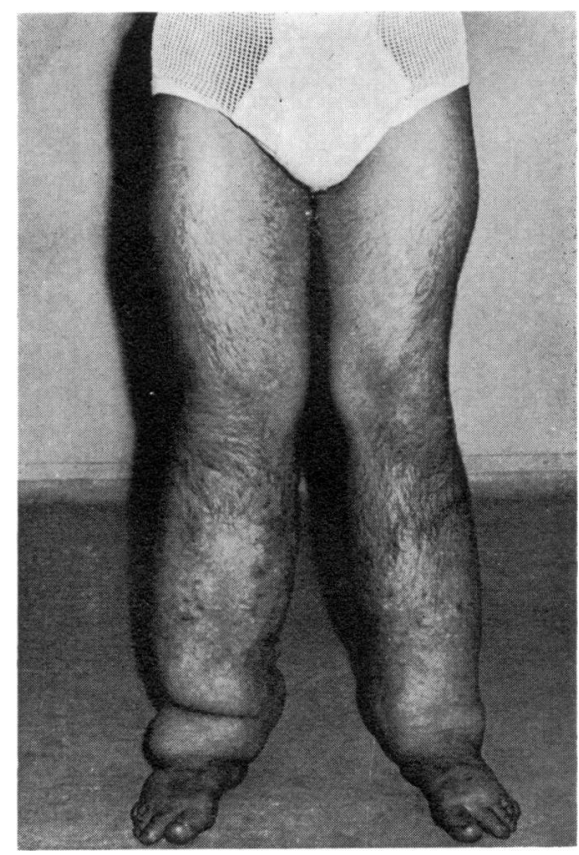

FIG. 3.-Severe lymphoedema of the elephantiasis type in patient $X I I I$, at age 27.

\section{Discussion}

The lymphangiograms were abnormal in all the patients so studied. In the one child where both a Patent blue screening test and a full lymphangiogram were made the screening test was normal, but the lymphangiography showed abnormally few lymph chains in the thigh. This is in conformity with the statement by Kinmonth et al. (1957) that smaller lymph vessel anomalies are not disclosed by the screening test.

The abnormal dye test in the smallest child, who was $2 \frac{1}{2}$ years old at examination, and the slightly abnormal lymphangiogram in the 8-year-old girl, point to pathology in the lymph vessels long preceding clinically apparent oedema. It suggests that the lymph vessel pathology is congenital, and is the cause of the oedema.

Hereditary lymphoedema is a condition known from before the turn of the century (Nonne, 1891; Milroy, 1892; Meige, 1898). In some families the oedema is present at birth and this condition is usually called Nonne-Milroy's syndrome, while the condition in families where the oedema is first present in later childhood, or around puberty, is called Meige's syndrome. In a survey on the literature up to that time (1950), Schroeder and Helweg-Larsen reported more than 50 families: the 
TABLE

Serum Protein Values at Different Ages, in Patients who Developed Obvious Oedema in Adult Life

\begin{tabular}{|c|c|c|c|c|c|c|c|c|c|}
\hline \multirow{3}{*}{$\begin{array}{c}\text { Patient } \\
\text { Pedigree No. }\end{array}$} & \multirow{3}{*}{ Age (yr.) } & \multirow{3}{*}{ Cholestasis } & \multicolumn{6}{|c|}{ Serum Proteins (g. $/ 100 \mathrm{ml}$. ) } & \multirow[b]{3}{*}{ Oedema } \\
\hline & & & \multirow{2}{*}{ Albumin } & \multicolumn{5}{|c|}{ Globulin } & \\
\hline & & & & Total & $\alpha_{1}$ & $\alpha_{2}$ & $\beta$ & $\gamma$ & \\
\hline XII $14(F)$ & 31 & No & $4 \cdot 1$ & & $0 \cdot 3$ & $0 \cdot 7$ & $0 \cdot 8$ & $1 \cdot 1$ & $++t$ \\
\hline XIII $7(\mathbf{M})$ & $\left\{\begin{array}{r}9 \\
13 \\
27\end{array}\right.$ & $\begin{array}{l}\text { Recently } \\
\text { No } \\
\text { No }\end{array}$ & $\begin{array}{l}2 \cdot 6 \\
4 \cdot 0 \\
3 \cdot 2\end{array}$ & $\begin{array}{l}1 \cdot 3 \\
1 \cdot 8\end{array}$ & $0 \cdot 2$ & 0.8 & $0 \cdot 6$ & $1 \cdot 1$ & $\begin{array}{c}+ \\
+++ \\
++t\end{array}$ \\
\hline XI $2(F)$ & $\left\{\begin{array}{r}3 \\
6 \\
23 \\
26\end{array}\right.$ & $\begin{array}{l}\text { Yes } \\
\text { Yes } \\
\text { Yes } \\
\text { No }\end{array}$ & $\begin{array}{l}3 \cdot 8 \\
4 \cdot 2 \\
4 \cdot 0 \\
3 \cdot 6\end{array}$ & $\begin{array}{l}2 \cdot 5 \\
2 \cdot 9\end{array}$ & $\begin{array}{l}0 \cdot 2 \\
0 \cdot 3\end{array}$ & $\begin{array}{l}0.5 \\
0.8\end{array}$ & $\begin{array}{l}0 \cdot 8 \\
0 \cdot 9\end{array}$ & $\begin{array}{l}0 \cdot 9 \\
1 \cdot 3\end{array}$ & $\begin{array}{c}0 \\
0 \\
+++ \\
+\end{array}$ \\
\hline XII $19(F)$ & $\left\{\begin{array}{l}22 \\
24\end{array}\right.$ & $\begin{array}{l}\text { Yes } \\
\text { No }\end{array}$ & $\begin{array}{l}2 \cdot 1 \\
4 \cdot 0\end{array}$ & & $\begin{array}{l}0.6 \\
0.2\end{array}$ & $\begin{array}{l}1 \cdot 0 \\
0 \cdot 7\end{array}$ & $\begin{array}{l}1 \cdot 4 \\
1 \cdot 0\end{array}$ & $\begin{array}{l}1 \cdot 7 \\
2 \cdot 3\end{array}$ & $\begin{array}{l}+++ \\
++t\end{array}$ \\
\hline XI $4(M)$ & $\left\{\begin{array}{l}15 \\
18\end{array}\right.$ & $\begin{array}{l}\text { No } \\
\text { No }\end{array}$ & $\begin{array}{l}4 \cdot 1 \\
3 \cdot 7\end{array}$ & & $\begin{array}{l}0 \cdot 3 \\
0 \cdot 3\end{array}$ & $\begin{array}{l}0 \cdot 5 \\
1 \cdot 1\end{array}$ & $\begin{array}{l}0.7 \\
0.9\end{array}$ & $\begin{array}{l}1 \cdot 2 \\
1 \cdot 6\end{array}$ & $\begin{array}{c}+++ \\
++\end{array}$ \\
\hline
\end{tabular}

members of about half the families showed oedema at birth and the other half showed oedema later. Of their own cases, one patient had oedema in one leg from birth and in the other leg from puberty, so that the difference between the two types is perhaps more quantitative than qualitative, and

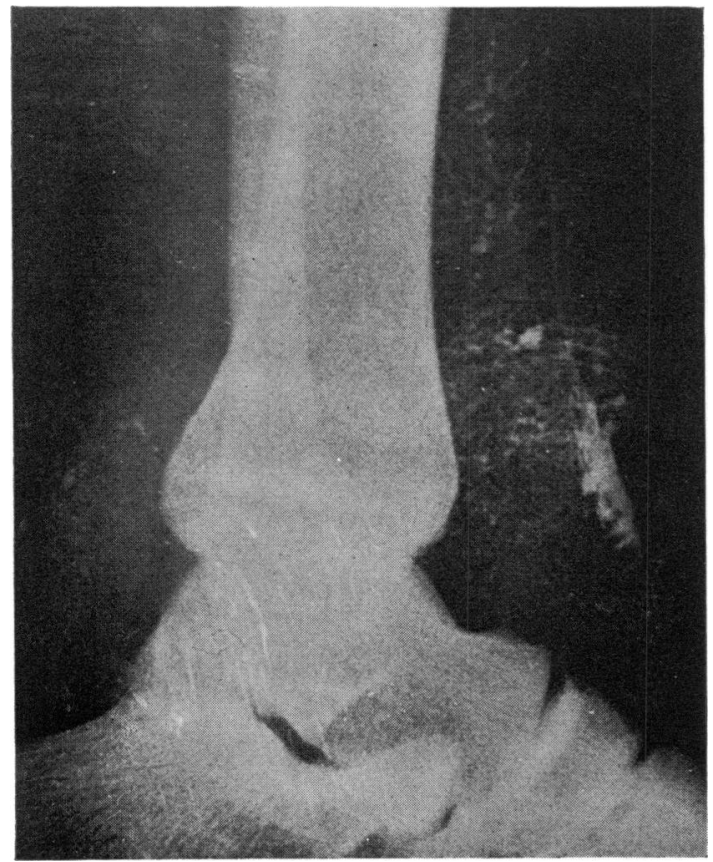

FIG. 4.-Lymphangiogram of one leg (patient XIII 7) showing lack of normal lymph chains and pronounced development of collaterals.

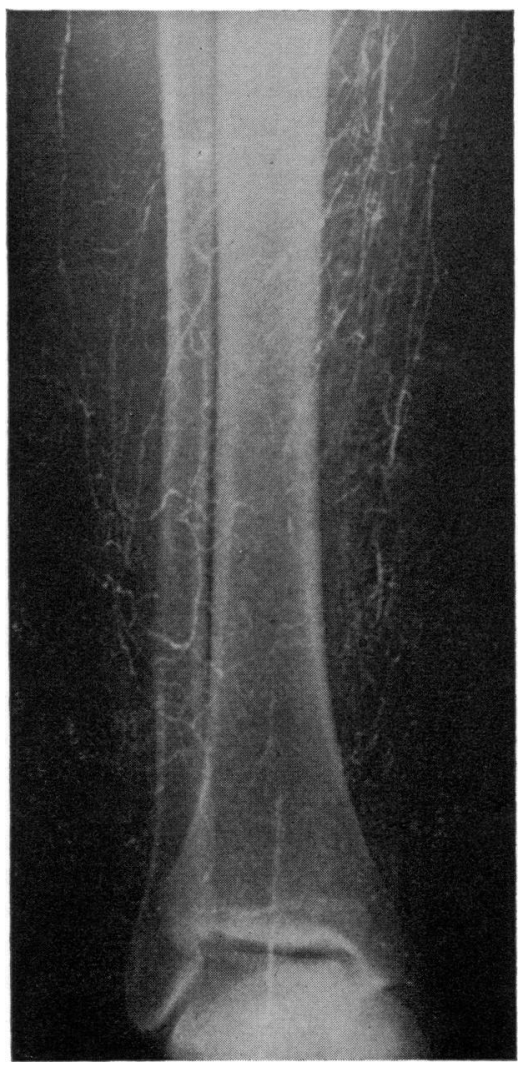

FIG. 5.-Lymphangiogram of patient XI 4 showing numerous collateral pathways and delayed clearing of the contrast 24 hours after injection. Some of the lymphatics appear slightly widened, probably the result of long-lasting stasis. 


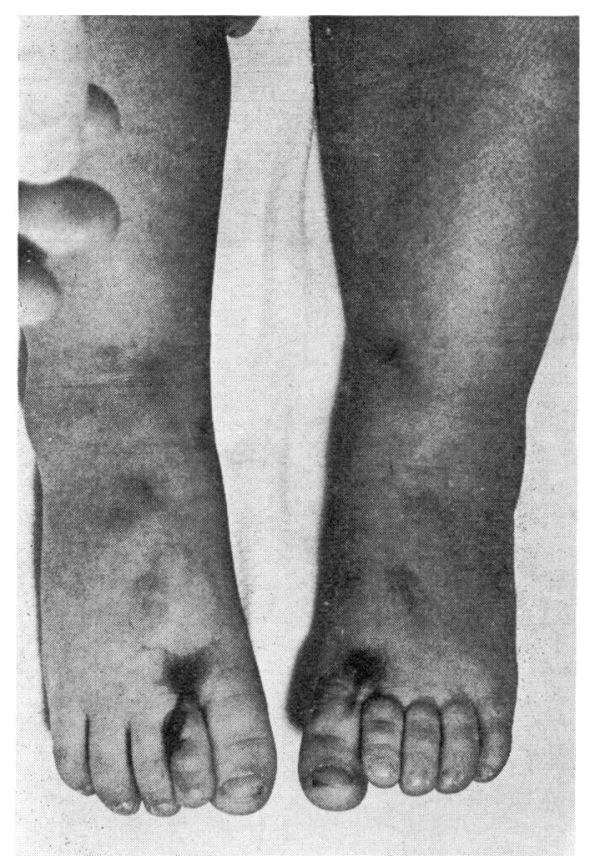

FIG. 6.-Intradermal injection of Patent blue in the first interdigital space in patient XIII 6, at age $2 \frac{1}{2}$ years, showed abnormal dermal back flow (the dark areas on the dorsum of the feet).

perhaps also a question of the type and location of a congenital lymph vessel pathology, as also suggested by Kinmonth et al. (1957).

Lymphatic pathology in regions other than the lower extremities is frequently present in patients with primary lymphoedema. Faber and Lusignan (1933) and Esterly (1965) found genital involvement, as we also did in our adult men (XIII 7 and XI 4). Quincke (1875) found a severe intestinal lymph pathology in a patient with hereditary lymphoedema in the legs, and this has been confirmed repeatedly in recent years. Of especial interest has been the combination of primary lymphoedema in the extremities with lymphatic anomalies in the intestine (causing protein-losing enteropathy) and sometimes with other primary lymph vessel anomalies such as chylous ascites and chylothorax (McKendry, Lindsay, and Gerstein, 1957; Pomerantz and Waldmann, 1963; and Kinmonth, Taylor, and Jantet, 1964). In no patients reported in the literature with peripheral and intra-abdominal lymph vessel pathology has liver function been abnormal.

The only earlier report of a combination of familial cholestasis and lymphoedema is by Sharp, Krivit, and Amplatz (1968); two sibs had cholestasis from the first weeks of life, biopsies from the liver at 6-8 weeks of age showed giant cell transformation. Both cases had congenital lymphoedema, with abnormal lymphangiography and dye screening test. Though the fact that the neonatal cholestatic period in these sibs lasted less than a year, that hyperlipaemia was absent, that the oedema was congenital rather than of the late (or Meige) type, and that the degree of fibrosis in the liver was more pronounced, the disease in these sibs seems to have been very similar to that in our family. Interestingly, both parents of these sibs were of Norwegian origin. Both in Sharp's patients and in ours no chromosomal abnormalities have been found.

All the adults in our series who had had cholestasis also had lymphoedema, while none had lymphoedema without having had cholestasis.

In the earlier report on this family (Aagenaes et al., 1968) we suggested a biochemical defect as the cause of the intrahepatic cholestasis. But with the present finding in these patients of an anatomical structural defect elsewhere a structural defect in the liver seems more likely.

This study was supported by a grant from Nordisk Insulinfond.

\section{REFERENCES}

Aagenaes, Ø., van der Hagen, C. B., and Refsum, S. (1968). Hereditary recurrent intrahepatic cholestasis from birth. Archives of Disease in Childhood, 43, 646.

Esterly, J. R. (1965). Congenital hereditary lymphoedema. fournal of Medical Genetics, 2, 93.

Faber, H. K., and Lusignan, H. R. (1933). Hereditary elephantiasis. American fournal of Diseases of Children, 46, 816.

Kinmonth, J. B., Taylor, G. W., and Harper, R. K. (1955). Lymphangiography. A technique for its clinical use in the lower limb. British Medical fournal, 1, 940.

- - - and Jantet, H. G. (1964). Chylous complications of primary lymphoedema. fournal of Cardiovascular Surgery, $\mathbf{5}, 327$.

Tracy, G. D., and Marsh, J. D. (1957). Primary lymphoedema. Clinical and lymphangiographic studies of series of 107 patients in which the lower limbs were affected. British fournal of Surgery, 45, 1.

McKendry, J. B. J., Lindsay, W. K., and Gerstein, M. C. (1957) Congenital defects of the lymphatics in infancy. Pediatrics, 19, 21.

Meige, H. (1898). Dystrophie oedémateuse héréditaire. Presse Médicale, 2, 341.

Milroy, W. F. (1892). An undescribed variety of hereditary oedema. New York Medical fournal, 56, 505.

Nonne, M. (1891). Vier Fälle von Elephantiasis congenita hereditaria. Virchows Archiv fur pathologische Anatomie und Physiologie und fur klinische Medizin, 125, 189.

Pomerantz, M., and Waldmann, T. A. (1963). Systemic lymphatic abnormalities associated with gastrointestinal protein loss secondary to intestinal lymphangiectasia. Gastroenterology, 45, 703.

Quincke, H. (1875). Ueber fetthaltige Transsudate. Hydrops chylosus und Hydrops adiposus. Deutsches Archiv für klinische Medizin, 16, 121. 
Schroeder, E., and Helweg-Larsen, H. F. (1950). Chronic heredtary lymphedema. Acta Medica Scandinavica, 137, 198.

Sharp, H., Krivit, W., and Amplatz, K. (1968). Familial infantile obstructive jaundice with persistent liver disease and lymphedema (abstr.). Gastroenterology, 56, 423.

Sigstad, H., Aagenaes, Ø., Bjørn-Hansen, R., and Rootwelt, $\mathbf{K}$ (1970). Studies in adult patients with hereditary cholestasis from birth and lymphoedema. Acta Medica Scandinavica. (In press.)

Correspondence to Dr. Ø. Aagenaes, Department of Paediatrics, University Hospital, Rikshospitalet, Oslo, 